\title{
INVESTIGATING READING COMPREHENSION THROUGH EEG
}

Luciane Baretta

Universidade Estadual do Centro-Oeste

Lêda Maria Braga Tomitch

Universidade Federal de Santa Catarina

Vanessa K. Lim

University of Auckland

Karen E. Waldie

University of Auckland

\section{Abstract}

Experimental studies point that different factors can influence reading comprehension, such as the topic, text type, reading task, and others. The advances in technologies for the past decades have provided researchers with several possibilities to investigate

\begin{tabular}{|l|l|l|l|l|}
\hline Ilha do Desterro & Florianópolis & $n^{\circ} 63$ & p. 069- 099 & jul/dez 2012 \\
\hline
\end{tabular}


what goes on in one's brain since their eyes meet the page until comprehension is achieved. Since the mid-80's, numerous studies have been conducted with the use of the electroencephalogram (EEG) to investigate the process of reading, through the analysis of different components - N400, N100 or N1, P2, among others. These components reveal, for example, how the brain integrates the meaning of a specific word in the semantic context of a given sentence. Based on previous studies, which demonstrate that different types of words affect cognitive load, this paper aims at investigating how the brain processes function and content words inserted in expository and narrative texts with suitable / unsuitable conclusions. Results showed that the type of text and word influence the cognitive load in different scalp areas (midline, right and left hemispheres). The N1s were more pronounced to the content words inserted in narrative texts and to the function words inserted in the expository type of texts, corroborating former studies.

Keywords: reading comprehension; EEG; brain

\section{Introduction}

Since the early days of the concept of cerebral dominance in the mid-1800s with Broca's and Wernicke's findings, a considerable amount of research has been carried out with brain damaged, callosotomized and hemispherectomized patients to understand the role of particular brain areas in different cognitive tasks (Bogen, 1997; Obler \& Gjerlow, 1999; Rosa, 2010). Scientists have used different methods including neuropathology, lesion studies, cerebral flow and metabolism, electric activity and stimulation (galvanism) and the effect of anesthetizing the hemispheres (the Wada test) together with different behavioral measures (e.g., finger tapping, eye and eyebrow movements) to investigate how the brain is organized for language (Code, 1997). 
The refinement of technology in the past years has contributed to theadvancesin tools that providea clearer picture to the understanding of what occurs in one's brain while they are performing a cognitive task, such as language production and comprehension. Besides offering precise information about lesion sites in living patients, techniques such as neuroimaging (Positron Emission TomographyPET, functional Magnetic Resonance Imaging-fMRI, near-infrared spectroscopy-NIRS) and electroencephalography (EEG) allow researchers to work with normal subjects when investigating brain processing and language-related tasks.

It is well known in the literature that converging evidence from clinical and neuroimaging studies points to left-hemisphere (LH) dominance for language organization and processing, including reading. Nevertheless, a host of clinical and neuroimaging studies also point that, although the right-hemisphere $(\mathrm{RH})$ does not appear to have much responsibility for core linguistic processes (syntax, morphology and semantics), it does contribute to some paralinguistic phenomena (intonation, stress), lexical interpretation (e.g., metaphors, homonyms), and the usage of context to interpret messages (Obler \& Gjerlow, 1999; Waldie, 2004), becoming therefore, an active participant in the processing of language, mainly in discourse comprehension (Gazzaniga et al., 1996; Heny, 1998; JungBeeman, 2005; Lundy-Ekman, 2000; Newman, Just \& Mason, 2004; Perfetti \& Bolger, 2004).

In the specific case of the reading skill, several neuroimaging studies (Nichelli et al., 1995; Scherer, 2007; St. George, Kutas, Martinez \& Sereno, 1999; Tomitch, Newman, Carpenter \& Just, 2008, among others) have demonstrated that the $\mathrm{RH}$ is active when one is performing reading comprehension tasks. Besides corroborating many of the assumptions raised through the observation of brain 
damaged patients, imaging data have shown that both right and left hemispheres tend to work conjointly in order to achieve meaning during discourse processing. Furthermore, results from these studies also signal that the level of involvement of different areas of the brain is variable and may be related to the type and demands of the task under investigation.

This paper intends to explore how the brain processes different types of texts with suitable/unsuitable conclusions. More specifically, this study aims at investigating, through the use of EEG, the involvement of the left and right hemispheres in the process of reading expository and narrative texts organized to present (un)suitable concluding sentences. In order to attain this objective, this article presents first, the basics of EEG and some of the studies that used this tool to investigate the process of reading comprehension and which provided the fundamentals for the design of the present research. Then, the method adopted to carry out this research is described and followed by data analysis. Finally, there is the discussion of the results.

\section{What is EEG, what are ERPs and how can they help in the understanding of language comprehension?}

There is a variety of non-invasive tools available to researchers to investigate the neural correlates of brain functioning. Before introducing the basics of EEG, the tool used in this research to study the neuronal correlates involved in the process of reading comprehension, an overview about the most used technologies applied to explore the brain will be presented, so as to situate EEG technology within the field of brain research.

The methods used to study the human brain can be categorized according to the type of information on brain activity they provide: 
high spatial or temporal resolution (OCDE, 2003). Among the techniques that have high spatial resolution, there are PET scan and fMRI. Both of these techniques use radioisotopes to monitor the increase of the blood flow, glucose and oxygenation in brain areas, assuming that those areas are involved in the performance of a given cognitive task, such as reading (Just, 2006, personal communication; Tomitch, Just \& Newman, 2004). A lesser-known technology: the near-infrared spectroscopy (NIRS), although only presenting reasonable spatial resolution, has excellent temporal sensitivity when compared to fMRI (Scherer, 2007). This tool has been considered a good alternative for behavioral studies given that its optical fibers allow subject's movement while performing a task. The techniques that provide high temporal resolution are magnetoencephalography (MEG), which registers the magnetic fields produced by neuronal activity, and electroencephalogram (EEG), which records the electrical brain activity. As already mentioned, given the fact that this research used EEG to investigate reading comprehension, this method will be discussed a bit further.

EEGstandsforElectroencephalogramorElectroencephalography. Traditionally, this tool has been associated with clinical use (e.g., brain disorder diagnostics, such as epilepsy and sleep disturbances), but advances in technologies have provided researchers the possibility of measuring brain activity associated with sensory and cognitive functioning by a different recording of electrical activity, the ERP, from event-related brain potential. Let us discuss each one of them.

Basically, EEG records the electrical activity of the brain considering the fact that transmission of information in the brain occurs through the flow of ions. Although the activity produced by a single neuron is only detected through intracranial recording, a larger population of neighboring neurons generates voltage fluctuation 
fields that can be detected from the scalp through the use of electrodes, making the EEG a non-intrusive technique to investigate on-going processing (Coles \& Rugg, 1995; Kutas \& van Petten, 1994). These voltage fluctuations produce traces of EEG which mirror the spontaneous electrical activity of the brain across time. The EEG gives good information about the general mental state (e.g., relaxed, alert, awake, sleeping) of a person. However, raw EEG is not sensitive enough to detect fine-grained changes in mental activity, such as the cognitive processes involved in discourse comprehension (Brown \& Haggort, 2000; Kutas \& Schmitt, 2003).

For this reason, a different aspect of the scalp-recorded activity, namely ERP - event-related brain potential - has been developed to obtain an estimate of activity which is time-locked or synchronized to some external stimuli or event, like reading a word, listening to a tune or seeing a picture. The ERP signal is relatively weak (5-10 $\mu \mathrm{V})$ when compared to the noisy EEG signal (50-100 $\mu \mathrm{V})$; therefore, it is necessary to extract the former from the latter by an averaging procedure. This is done by time-locking multiple trials of EEG traces which are then averaged to eliminate the spontaneous (noisy EEG) activity and to maintain the event-related brain activity (Coles \& Rugg, 1995). In order to obtain good clean average ERPs, the number of trials in cognitive experiments range from 30 to 50 for each type of stimulus (Brown \& Haggort, 2000).

The EEG as well as the ERP signals are measured in relation to a reference electrode, placed on the subject's earlobe, chin, or at the central area of the scalp, known as $\mathrm{Cz}$, in accord with the international 10-20 system. The comparison of the electrical signals between the reference and the other electrodes, placed in a variety of predetermined locations, according to the objective of the study, 
allows researchers to measure the difference in brain activity across the different areas of the scalp.

ERP waveforms are commonly interpreted and represented according to three different parameters: amplitude (calculated in $\mu \mathrm{V}$, relative to a baseline), latency (delay from stimulus onset) and polarity ( $\mathrm{P}$ for positive and $\mathrm{N}$ for negative). The positive and negativegoing fluctuations that can be visualized in any ERP waveform are defined as components and are labeled as a function of their polarity and their latency (in $\mathrm{msec}$ ). For instance, N400 represents a negative change in amplitude - compared to a baseline prior to stimulus onset - occurring at about $400 \mathrm{msec}$ after the onset of the stimulus or event of interest (Kutas \& Schmitt, 2003).

In general terms, researchers believe that components that occur prior to $100 \mathrm{~ms}$ are associated with information processing at the sensory level. They are considered to be exogenous or stimulus-bound because they tend to be not affected by a subject's state of alertness/ attentiveness. Long-latency or endogenous components, on the other hand, are the more informative brain waves which are elicited by perceptual and cognitive operations that may occur as a subject processes a given stimulus, for instance, reading a sentence (Coles \& Rugg, 1995; Kutas \& Schmitt, 2003). The endogenous components have been the focus of higher order cognitive function studies, such as language. Some of the commonly ERP components investigated in language comprehension and production are briefly described next.

The N400 is probably one of the most investigated components, since the publication of the seminal article by Kutas and Hillyard in 1983 on semantic processing of written sentences. The N400 component is a negative wave, peaking at about $400 \mathrm{msec}$ and is associated with readers' difficulty in integrating a lexical element in 
the preceding context. The N100 or N1 and P2 are elicited by auditory and visual stimuli and reflect early sensory and attentional processes associated with one's ability to process a channel of information (Raney, 1983). The $\mathrm{P} 300$ is a positive component that is elicited by any stimuli requiring a binary decision (e.g., word versus non-word) and it tends to be sensitive to one's confidence in performing the task (Kutas \& van Petten, 1994). The P600 or the syntactic positive shift (SPS) is a late peak elicited by syntactic violations (Kutas \& Schmitt, 2003).

EEG has been used in a considerable number of language studies for the past years (Baretta, Tomitch, MacNair, Lim \& Waldie, 2009; Coulson \& Lovett, 2004; Coulson \& van Petten, 2002; Federmeier, May \& Kutas, 2005; Federmeier \& Kutas, 1999; Kutas \& Hillyard, 1983, 1984; Mueller, Hirotani \& Friederici, 2007; Raney, 1993; St. George, 1995; St. George, Mannes and Hoffman, 1994, among others). Given the fact that the present study uses EEG to investigate cognitive load in reading, the following section will review the studies that provided the fundamentals for the design of this research.

\section{EEG and the study of reading comprehension}

The articles written by Kutas and Hillyard, published in 1983 and 1984, are placed among the first studies to report that EEG was a valid tool to investigate different aspects of language processing, such as reading comprehension. In their 1984 study, when analyzing the final words that completed sentences in a meaningful way but that varied in terms of semantic expectancy (high, medium or low expectation for the ending), the authors observed that unexpected words produced a larger N400 wave than predictable words. In sentences such as: He liked lemon and sugar in his (coffee/tea), the word coffee, although semantically related to the context, is 
unexpected and somehow incongruous, causing surprise in the reader, generating greater N400 peaks than the word tea. Results also showed differences in the processing of closed- (function) and open-class (content) words: ERPs elicited by closed words tended to be symmetrical over the two hemispheres, whereas the open-class words elicited a more pronounced wave in the $\mathrm{LH}$, demonstrating that the cerebral hemispheres process words differently. Kutas and Hillyard proposed that the findings of their study suggest that ERPs and particularly the N400 component is a valid index of semantic priming or activation.

Since these two studies were published, many experiments have been carried out in order to investigate the processes that integrate the meaning of a particular word into its sentence-semantic context (e.g., Baretta et al., 2009; Coulson \& van Petten, 2002; Federmeier et al., 1999, 2005; Mueller et al., 2007; St. George et al., 1994, 1997; St. George, 1995; van Berkum, Haggort \& Brown, 1999). In order to enhance the possibility to use EEG to investigate language processes, St. George et al. (1994) investigated whether the ERPs were sensitive to more global contexts than the focal sentence. To attain this objective, the authors compared the reading of words of titled and untitled paragraphs, which without the presence of the title seemed unrelated and semantically vague in terms of global meaning. Analysis of the N400 component demonstrated that readers faced more difficulties to understand the paragraphs without a title, suggesting that the presence of a title makes certain aspects of reading easier, mainly those related to high level processes, such as integration and maintenance of information. In addition, differences in early ERP components between titled and untitled conditions suggested that the presence of global coherence frees the reader's capacity of attention to be allocated to the processing of words. This 
study was one of the firsts to provide evidence that ERPs can be used to measure on-line cognitive processes at the discourse level.

Following this line of thought, St. George (1995) investigated the process of inference making while subjects read four-sentence long passages. Results showed that high working memory capacity readers were more prone to generate inferences, counter to lower spans, who made only the bridging - obligatory - type of inference. As reasoned by St. George, it is probable that lower span readers were less able to generate the elaborative - non obligatory - inferences because their working memory was taxed with function words, as demonstrated by the greater $\mathrm{N} 400$ responses that possibly indicate these readers' difficulty in integrating these words into a coherent textbase. In a study with expository and narrative types of texts, conducted by Baretta et al. (2009), some different results were observed. Analyses of the N400 demonstrated that subjects generated inferences even before they were presented in the text and that the expository type of text was more difficult to process than narration, as revealed by the larger N400 peaks.

In a former study, Raney (1993) observed that different task demands affect cognitive load in reading, i.e., the mental effort required to perform a task. In a series of three experiments, the author examined the effect of a secondary task on the first and second reading of the same text, and found that readers tended to show a reduction in cognitive load when reading the text for the second time, as revealed by an increase in the N1-P2 amplitude. As explained by the author, when subjects read the text for the first time, more total capacity was used for comprehension, increasing the cognitive load of the readers, leaving them fewer resources to process low-level demands, such as letter and word analysis, as indexed by 
low N1-P2 amplitudes. These results, together with other findings of the study, suggest, as Raney points out, that readers were able to allocate their attentional resources depending on their objectives of reading and on the demands imposed by the task.

The studies conducted by Raney (1993), St. George et al. (1994), and St. George (1995), using the EEG technique, suggest that when readers are facing difficulty to integrate information into a coherent text, they have fewer resources to allocate for word encoding. That is to say, depending on the complexity of the text and/or the competing reading task, the greater the cognitive load of the readers (the amount of mental effort required by a task, as indexed by the N1 component), leaving them fewer resources to assign for lower level processes, such as word encoding.

Considering the data of the aforementioned studies, the present research intends to investigate if the brain processes content and function words differently - in terms of the cognitive load - when they are embedded in narrative and expository texts. The rationale to analyze the possible differences in terms of brain processing when different word classes are presented in different types of text comes from previous EEG studies that discriminated words into content and function classes (St George, 1995; St. George et al., 1994; 1997; van Petten, 1995), and showed that there are differences in terms of the electrical signal generated by each class of words, suggesting that the brain interprets these words in a different fashion. Having this in mind, and given the evidence provided by the literature that narration is easier to understand than exposition, that is to say, that more cognitive load would be necessary to read exposition, this study was designed. 


\section{Method}

\section{Participants}

Fourteen male, right-handed subjects participated in this study. All subjects were native speakers of English and university students in Auckland, New Zealand. Their average age was 22 years. The subjects had normal visual acuity with no known language impairment or any neurological or psychiatric disorders. Each subject read and signed a consent form approved by the University of Auckland Human Participants Ethics Committee.

Data acquisition: EEG recording

The EEG was recorded continuously with a sampling rate of 1000 $\mathrm{Hz}$, using an electrical Geodesics Inc. (EGI) 128-channel Ag/AgCl electrode net (Electrical Geodesics Inc., Eugene, OR, USA). All the electrodes were referred to a common vertex $(\mathrm{Cz})$ on line and later re-referenced to an average of the left and right mastoid sites. Thirteen sites were considered for this study: midline frontal $(\mathrm{Fz})$, central $(\mathrm{Cz})$ and parietal $(\mathrm{Pz})$ recording sites were used, along with lateral pairs of electrodes over frontal (F7 and F8) and central (C3 and C4) scalp as defined by the 10-20 system (Jasper, 1958). Three lateral pairs were also used: (1) an anterior temporal pair placed midway between F7- T3 and F8 - T4 (approximately over Broca's area and its right hemisphere homologue); (2) a temporal pair placed 33\% lateral to $\mathrm{Cz}$ and (3) an occipital pair placed midway between $\mathrm{T} 5$ - O1 and T6 - O2. The selection of electrodes was based on previous EEG research on sentence- and discourse-level (St. George et al., 1997 and van Berkum et al., 1999). 
Figure 1 - Headmap with the electrodes considered in this study

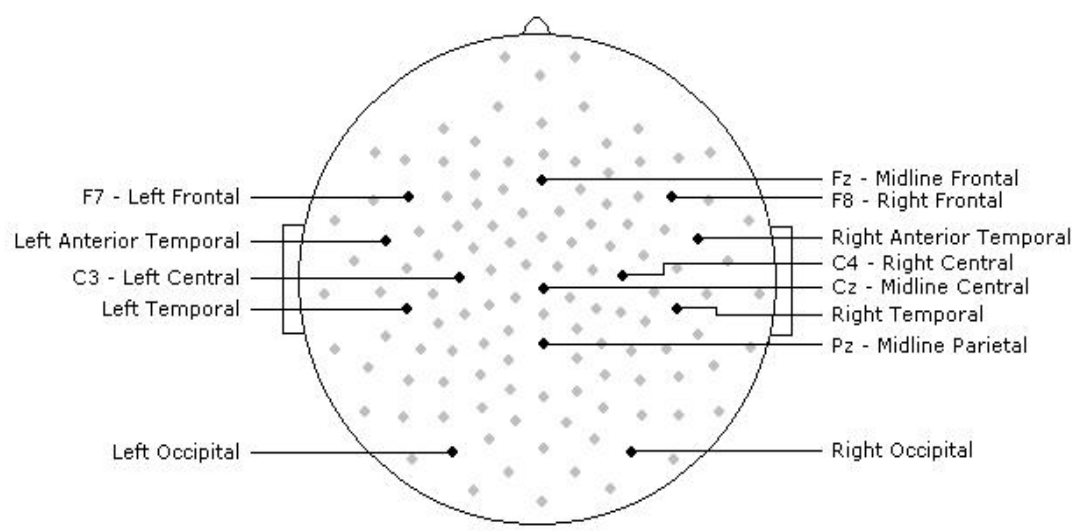

\section{Stimuli}

The stimuli consisted of 30 narrative paragraphs that were based on a previous study conducted by St. George (1995) and 30 original expository paragraphs adapted from naturally occurring texts in English to satisfy the requirements of the experiment. All the paragraphs were four-sentence long; the length of the sentences ranged from 4 to 14 words (mean $=8.4$ words). Each paragraph addressed a different situation or fact and contained information related to general knowledge, i.e., education, health, technology, hobbies, leisure, work life, everyday routine and so on. The paragraphs were structured to present congruent/incongruent condition versions (see Table 1 below). The congruent condition illustrates a paragraph organized in a way that the first three sentences suggest the conclusion stated in the fourth sentence. The incongruent condition 
represents the paragraphs that, although may sound coherent in the first three sentences, do not lead to the conclusion stated in the fourth sentence, causing surprise in the reader when reading the final sentence. The first and the last sentence were the same for both conditions of a paragraph, but subjects read only one of the versions of each paragraph.

Table 1 - Sample paragraphs

Expository paragraph

\begin{tabular}{ll}
\hline Congruent condition & Incongruent condition \\
\hline The XE Universal Currency & The XE Universal Currency \\
Converter is a straightforward web & Converter is a straightforward \\
site. (situation) & web site. (situation) \\
People can make currency & It helps people to find \\
conversions in a matter of seconds. & information about the \\
(eliciting a conclusion) & history of money. (eliciting a \\
& conclusion) \\
The site includes all the world's & The site was developed by \\
currencies. (supporting & a historian. (supporting \\
information) & information) \\
Currency conversion is made easy & Currency conversion is \\
with technology.(conclusion) & made easy with technology. \\
& (conclusion) \\
\hline
\end{tabular}

Narrative paragraph

\section{Congruent condition}

His parents wanted to surprise him with something special for Christmas. (setting the scene)

\section{Incongruent condition}

His parents wanted to surprise him with something special for Christmas. (setting the scene) 
He had never had a pet before.

He had never had a bike before.

(eliciting an outcome) (details of the scenario)

On Christmas morning he awoke All his friends had them.

to the sound of barking from (details of the scenario)

the living room. (supporting information)

His parents had gotten him a His parents had gotten him a puppy. (conclusion) puppy. (conclusion)

\section{Procedure}

Subjects were run individually in one session lasting approximately 90 minutes. Data collection was divided into two parts. In the first part, subjects received explanation about the experiment, read and signed their informed consents and received training for the experiment. In the second part, after the set-up of the EEG net, subjects were tested in an electrically shielded chamber. They sat in a chair, approximately $57 \mathrm{~cm}$ in front of a computer monitor and were instructed to read 60 paragraphs for comprehension and judge whether the last sentence of each paragraph was a suitable conclusion for that paragraph, by pressing " 1 " or " 2 " after the prompt "Agree $=1$ / Disagree $=2$ " appeared on the screen. This procedure was adopted in order to ascertain that subjects were in fact processing the information presented. The initiation of each paragraph was controlled by the subject, by pressing any key in the keyboard. The paragraphs were presented word by word in black lowercase Arial letters, being the first letter of each sentence presented in capital letter against a white background, in the center of the computer screen. The trials were presented in two blocks with 30 paragraphs each, with a break of 3 to 5 minutes between the trials. Each subject 
read a set of 60 paragraphs. Two sets of 60 paragraphs (15 paragraphs $\mathrm{x} 2$ condition types: congruent, incongruent $\mathrm{x} 2$ types of text: narrative, exposition) were organized so that both types of texts were represented equally across the conditions.

\section{Analysis of results}

The N100 or simply N1 component is a negative wave that occurs at approximately $100 \mathrm{msec}$ post-stimulus. Although this component is commonly investigated in auditory and visual discrimination paradigms, the N1 was adopted in this study to investigate subjects' cognitive load while reading the words presented in both third and fourth sentences of the congruent / incongruent paragraphs. As mentioned above, in the section EEG and the study of reading comprehension, the rationale for using this component as a valuable measure of attentional capacity is based on previous studies that suggest that the N1 reflects low-level processes, such as word encoding (Raney, 1993; St. George, 1995; St. George et al., 1994). According to these researchers, when subjects are facing difficulty to integrate sentence information into a coherent text, they have fewer resources to allocate for word encoding, which is revealed by low N1 amplitudes. Lower N1s can be interpreted, then, as the subjects' greater involvement in the process of making sense of the text, or in the case of this study, the subjects' involvement in judging whether the last sentence of each paragraph was an adequate conclusion.

The N1 data generated by the words in the final and third sentences of each paragraph was analyzed according to the 85-135 msec time-window. EEG recordings for each subject were averaged across all trials per condition, generating waveforms of the words presented in each paragraph type, for each scalp area for each subject. 
The data from the paragraphs were sorted as Text Type (narrative, expository text), Paragraph Condition (congruent, incongruent) and Word Type (content, function) for both third and fourth sentences separately. The distinction between content and function words differ, in several aspects and may be controversial according to some theories, (e.g., the relevance theory, as proposed by Sperber \& Wilson (1995)). This study adopts the definition used in former EEG studies (Raney, 1993; St. George, 1995; St. George et al., 1994). Content (or major and, also, open) words are those belonging to the major part of speech classes: nouns, verbs, most adjectives and the -ly adverbs in English. These words tend to be numerous and open-ended, since an unlimited number of new words can be created and added to these classes (e.g., I teach, the teacher(s), s/he teaches, the teaching). Function (or minor and, also, closed) words are those related to grammatical classes, which tend to include a small number of fixed elements: auxiliary verbs (was), articles, complementizers (which), conjunctions, sentence connectors, interrogatives, verb particles, prepositions, pronouns and some adjectives and adverbs. The data for the fourth sentence will be presented first, followed by the data generated by the third sentence.

\section{N1: sentence four}

A two-way repeated-measures ANOVA with paragraph type (exposition congruent, exposition incongruent, narrative congruent, narrative incongruent) and scalp site (13 levels) as factors was conducted to verify amplitude differences between paragraph types. The main effect of scalp site was significant $(\mathrm{F}(12,156)=6.876, \mathrm{p}=$ $<.002$ ) (see Figures 2 and 3 below for differences in amplitudes). No other main or interaction effects were found. Although not statistically significant, it is interesting to observe that the electrodes 
located at central, frontal and temporal areas yielded smaller N1s in the LH for the expository type of text and in the $\mathrm{RH}$ for narration. The other electrodes located at later-temporal and occipital areas yielded smaller N1s for both types of text.

Figure 2 - Average waveforms for each site for the Expository congruent (solid blue line) and Expository incongruent (dotted pink line) conditions. The electrodes are referred to their location and correspond respectively to electrodes (from left to right, top to bottom): 11, 129, 62, 122, 104, 115, 102, 90, 33, 36, 39, 46, 65. Negativity is plotted up.

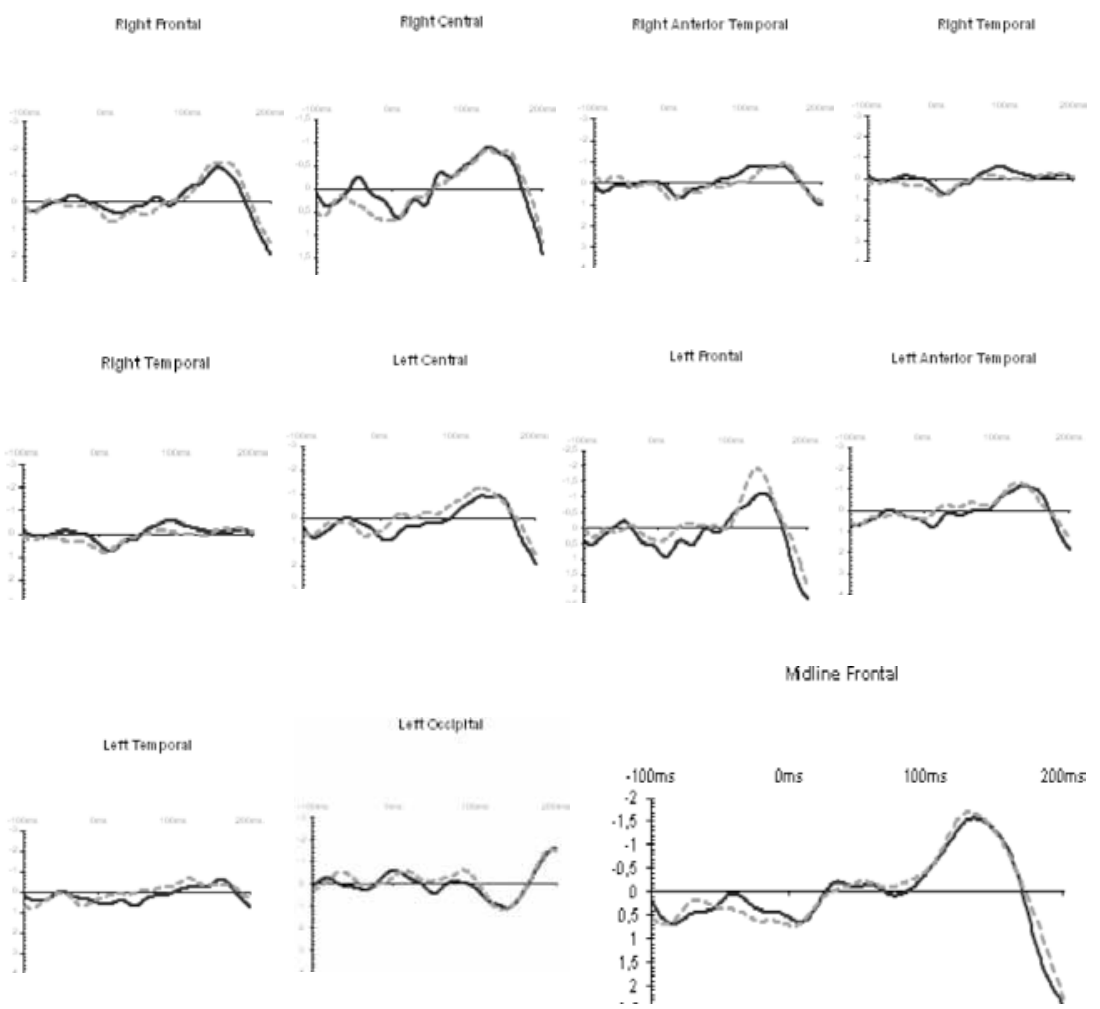




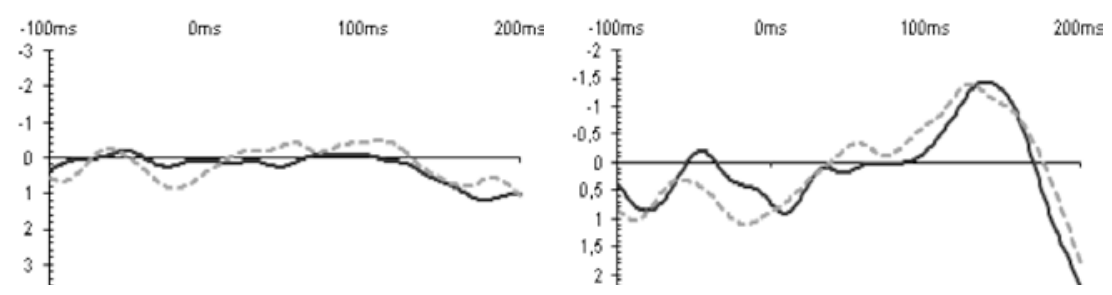

Figure 3 - Average waveforms for each site for the Narrative congruent (solid blue line) and Narrative incongruent (dotted pink line) conditions. The electrodes are referred to their location and correspond respectively to electrodes (from left to right, top to bottom): 11, 129, 62, 122, 104, 115, 102, 90, 33, 36, 39, 46, 65. Negativity is plotted up.

Molline Frontal

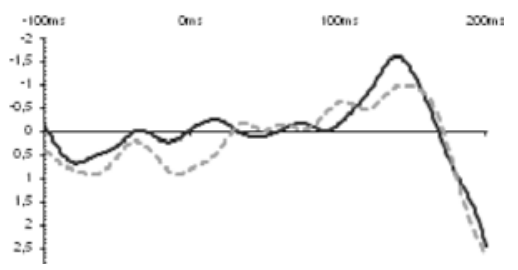

Midine Central

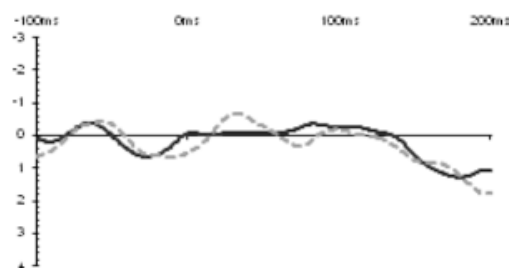

Right Frontal

Right Central

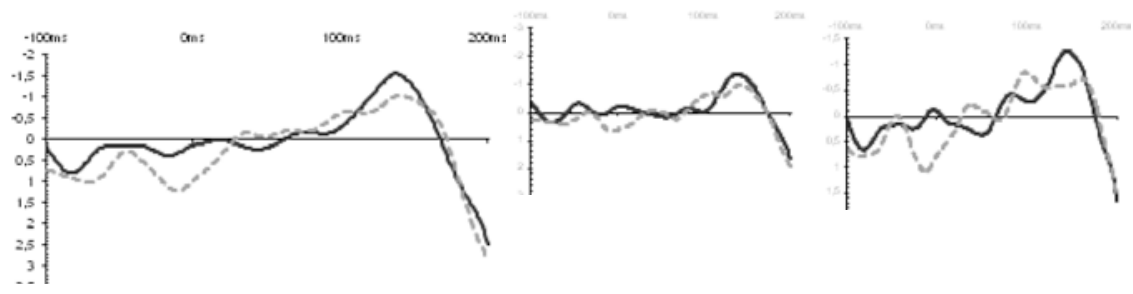


Fight Anterior Temporal

Fight Temporal

Fight Ocsipltal
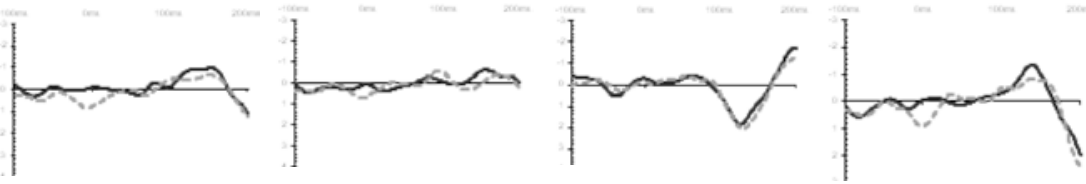

Lent Freatil

lottinterter Tomperal

tottremperal

tertceolpits
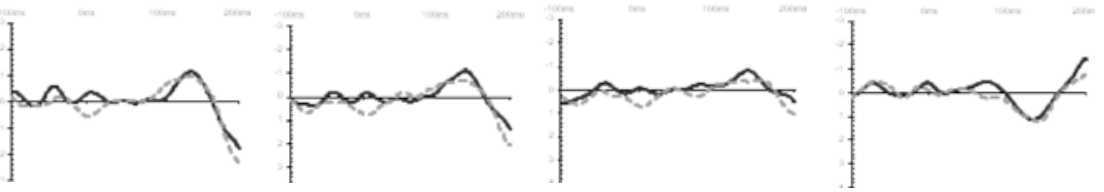

A three-way repeated-measures ANOVA with type of word (content, function), text type (exposition, narrative) and scalp area (midline, $\mathrm{RH}, \mathrm{LH}$ ) as factors was conducted to investigate possible amplitude differences between type of word and text type at three scalp areas. The analysis showed significant main effects of scalp area $(\mathrm{F}(2,26)=20.740, p=<.001)$ and type of word $(\mathrm{F}(1,13)=19.403, p=$ $.001)$ and significant interactions between scalp area and type of word $(\mathrm{F}(2,26)=7.351, p=.004)$ and text type and word $(\mathrm{F}(1,13)=7.661$, $p=.016)$. No other significant main or interaction effects were found. For the main effect of scalp area, mean N1 amplitudes were lower in the $\mathrm{RH}($ mean $=-1.3 \mu \mathrm{V})$, followed by the $\mathrm{LH}($ mean $=-1.49 \mu \mathrm{V})$ and by the midline area $($ mean $=-1.98 \mu \mathrm{V})$. Pair-wise comparisons demonstrate there is a significant difference in the N1 amplitudes between midline area and RH $(p<.001)$ and median area and LH $(p<$. 006) but not between RH and LH ( $p>$.05).

The N1 amplitudes for the main effect of type of word were lower for function words (mean $=-1.33 \mu \mathrm{V}$ ) than for content words 
$($ mean $=-1.84 \mu \mathrm{V})$. The interactions between scalp area and type of word and text type and type of word are illustrated in Figure 4 below.

\section{N1: sentence three}

Another ANOVA with data from the third sentence with type of word (content, function), text type (exposition, narrative) and scalp area (midline, RH, LH) as factors was conducted to investigate N1 amplitude differences between type of word and text type at three scalp areas. The analysis showed highly significant main effects of scalp area $(\mathrm{F}(2,26)=12.773, p=<.001)$ and type of word $(\mathrm{F}(1,13)=$ $29.232, p=<.001)$ and significant interactions between scalp area and type of word $(\mathrm{F}(2,26)=9.831, p=.001)$ and text type and word ( $\mathrm{F}(1$, $13)=5.602, p=.034)$. No other significant main or interaction effects were found.

The lower amplitudes were measured in the RH (mean $=-1.31$ $\mu \mathrm{V}$ ), followed by the LH (mean $=-1.41 \mu \mathrm{V}$ ) and by the midline area $($ mean $=-1.81 \mu \mathrm{V})$. Pair-wise comparisons reveal there is a significant difference in the $\mathrm{N} 1$ amplitudes between midline and RH $(p=.004)$ and midline and LH $(p=.009)$ but not between RH and LH $(p>05)$. The main effect of type of word shows that the lower N1s were measured for function words (mean $=-1.18 \mu \mathrm{V}$ ), which differs significantly from the content words (mean $=-1.84$ $\mu \mathrm{V})$. The interaction between scalp area and type of word revealed that function words amplitudes were lower than content words in all scalp areas. The interaction between text type and type of word showed that both expository and narrative types of text yielded lower N1 amplitudes for function words. 
90 Luciane Baretta et al., Investigating reading comprehension...

Figure 4 - Means for the interaction between scalp area and type of word and text type

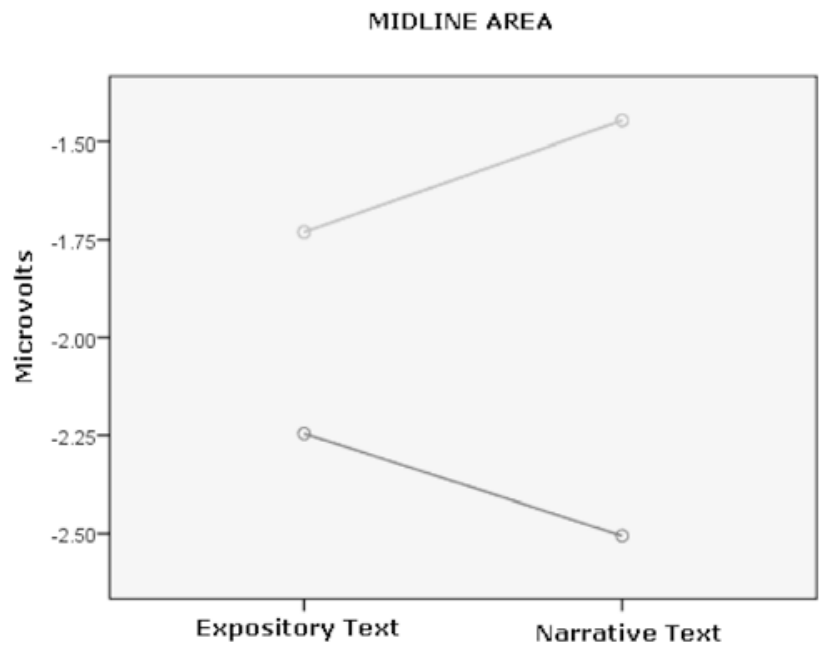

Type of word

Content

- Function

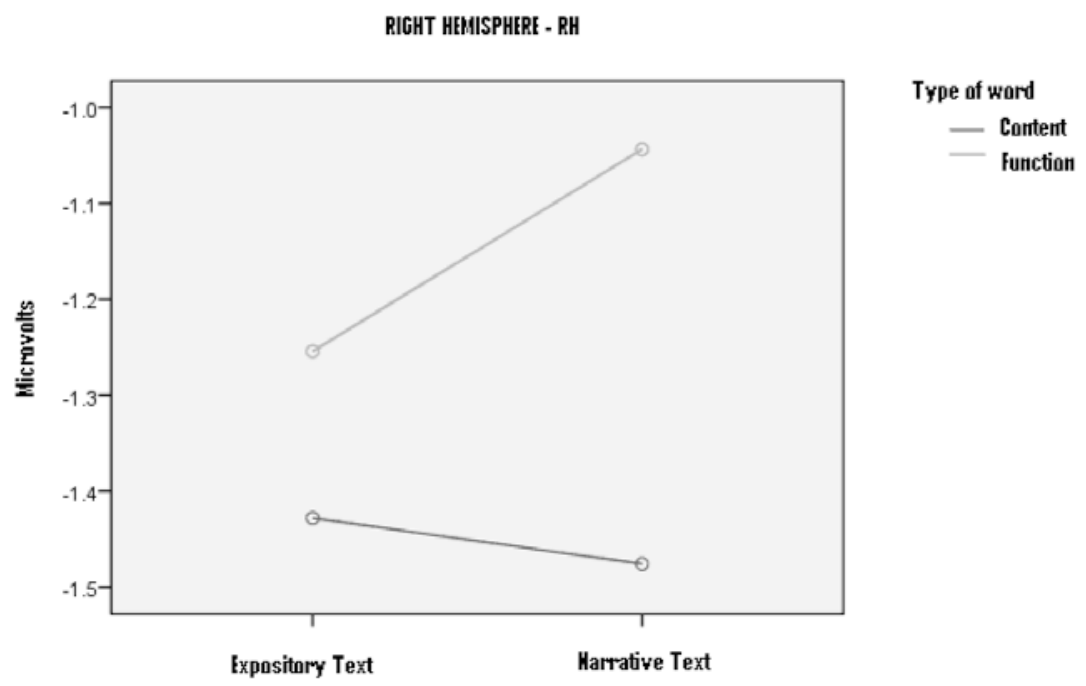




\section{IEFT HEMISPHERE - IH}

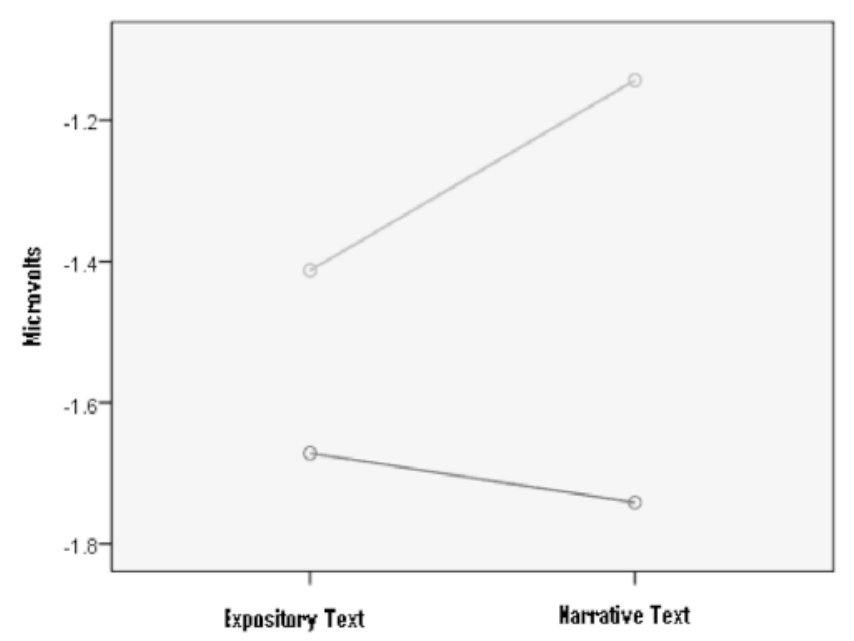

Type of Word

- Content

- Function

\section{Discussion}

Analysis of results revealed that the N1 peaks were larger for content words in the narrative type of text and function words in the expository type of text, in all the three scalp areas, suggesting that subjects approached/read the two types of texts differently. As shown in Figure 2, there are considerable differences in the N1 amplitudes for the type of word across text types. As the figures demonstrate, the function words elicited lower N1 amplitudes when compared to the content words in all the selected sites signaling subjects' cognitive load to process those words. When reading the narrative paragraphs, subjects seemed to devote more attention to function words, as revealed by the low N1s, than when reading the expository paragraphs. For this type of text, subjects tended to adopt a balance between content and function words, that is, they seemed to share their cognitive resources to process both types of words in a similar fashion. 
The overall N1 amplitudes for function words in the fourth sentence demonstrated a considerable increase, and this can be interpreted as a reduction in the cognitive resources devoted to this type of words in detriment of other lower or higher-order processes. It is interesting to mention, however, that the larger $\mathrm{N} 1$ amplitudes were yielded mainly at the midline area and in the LH. In the RH, the $\mathrm{N} 1$ for function words revealed somewhat similar amplitudes for both the third and fourth sentences across the two types of texts. This finding seems to indicate that, besides the fact that subjects approached the two texts differently, (as measured by the different amplitudes for function words), the RH was differently involved in the process of reading for global coherence, as expected. According to the literature, the RH tends to maintain various interpretations or distant semantic relations of words weakly activated (Beeman, 1993; Beeman et al., 2000; Virtue et al., 2006(b)), a role that has demonstrated to be quite important to the process of determining global coherence (Mason \& Just, 2004; Schmalhofer, 2005; Virtue et al., 2006(a); 2006(b)). The LH, on the other hand, is specialized in strong activation of smaller semantic fields, focusing on the concepts directly related to the information being processed. This is what the N1 data appear to demonstrate. While the RH showed a similar pattern of focal attention to content and function words while the third and fourth sentences were being processed, probably when inferences were being generated and integrated into discourse, the LH demonstrated more involvement with function words in the third sentence, only. This probably occurred because it was during sentence three that hypotheses for plausible conclusions were being raised and, as so, the syntactic relations had to be correctly interpreted to be incorporated into the ongoing process of reaching a conclusion for the paragraphs (see Baretta et al. (2009) for a discussion of 
results related to third and fourth sentences, considering the N400 component). In sentence four, when the conclusion was being integrated into discourse, the $\mathrm{LH}$ demonstrated less involvement with function words, possibly in detriment of decoding, which could receive more attention given the fact that the information being read - the conclusion - matched the previously generated inference / hypothesis. The RH, on the other hand, given its coarse semantic coding (Beeman et al., 2000), tended to maintain a similar pattern of activation for both types of words.

Regarding the interaction between type of word and text type. As already mentioned in the section N1: Sentence four above, the results concerning the $\mathrm{N} 1$ component in the fourth sentence seem to suggest that subjects tended to approach exposition and narration differently. This interpretation was based on the finding that the N1s for function words in the narrative text were lower than the N1s in the expository text. Having in mind the assumption raised in relation to the N1 component previously, that is to say, that lower N1s would indicate cognitive load (more difficulty in processing input), it seems plausible to conclude that the reading of the fourth sentence of narrative paragraphs was somewhat more demanding than the reading of expository paragraphs. At first, this finding seemed to contradict the results related to the third sentence, that is, that the low N1s for the expository paragraphs signaled that this type of text was more demanding than narrative. Nonetheless, when behavioral results are considered, that is, subjects were better at judging the (un) suitability of the last sentence of expository paragraphs, the lower N1s for function words in narration in the fourth sentence appear to make sense. It seems reasonable to conclude, therefore, that the EEG data related to the fourth sentence of these paragraphs is consonant to the behavioral findings, for it demonstrates the subjects' cognitive 
load in integrating the function words of narrative paragraphs into connected discourse, as demonstrated by the lower scores in performance in that type of text.

In relation to the significant interaction between scalp area, type of word and text type, it is possible to notice that there was an overall tendency towards lower N1s for function words in both types of texts, across all scalp areas (midline, $\mathrm{RH}$ and $\mathrm{LH}$ ). The biggest difference - between content and function words - was found at the midline area in both third and fourth sentences. Nevertheless, given that this investigation is particularly interested in the involvement of the $\mathrm{RH}$ and LF in the process of reading comprehension, the discussion of results will be focused on the two hemispheres.

In the RH the difference between content and function words (although not statistically significant) was smaller than in the LH, for both types of texts in both sentences, except in sentence three in the expository type of text, where the LH showed a smaller difference between content and function words than the RH did. This finding, although puzzling, appears to be in agreement with what Virtue et al. (2006b) have argued as regards the generation of bridging (obligatory) inferences. According to these authors, since bridging inferences tend to be more constrained by the text, it is possible that the $\mathrm{LH}$ shows greater involvement than the $\mathrm{RH}$ in the process of semantic information, i.e., content words. Thus, given the structure of the expository type of text and that subjects were in the process of generating a possible conclusion in sentence three, as argued above, it seems reasonable to assume that the LH had a greater participation in this process in exposition, as demonstrated by the similar N1s for both content and function words. Even though one may speculate that this pattern should also have occurred in the fourth sentence, mainly because of the constrained structure of exposition, this was 
not the case. There is, however, a plausible explanation for this. It is possible that, given the reading purpose of the task, i.e., read to judge the suitability of the last sentence, the RH "assumed the control" in sentence four, once it was necessary to have a coarse interpretation of the paragraph in order to perform the behavioral task. Therefore, since the $\mathrm{RH}$ is specialized in global processing, it seems reasonable to conclude that this hemisphere had to take the lead in sentence four, once subjects had to consider the information presented in the whole paragraph, in order to decide whether the last sentence fit the overall semantics of the just read text.

\section{Final remarks}

The purpose of this study was to explore, through the use of a technological tool, the involvement of the left and right hemispheres in the process of reading expository and narrative texts for global comprehension. In the present study, this investigation was mostly based on the processing of function and content words of the third and final sentences of congruent / incongruent paragraphs. Overall, function and content words showed a similar pattern of focused attention (as demonstrated by lower N1s) in the RH, demonstrating a relatively coarser semantic coding. The LH, on the other hand, seemed to prioritize one class of word (content or function) to process, demonstrating a relatively fine-grained computation, in accord with what is proposed by Jung-Beeman (2005). The results brought by the present study raise some interesting issues that deserve further research, especially when involving the use of EEG and behavioral responses related to language processing and cognition. 


\section{References}

Baretta, L., Tomitch, L.M.B., Mcnair, N., Lim, V.K. \& Waldie, K.E. (2009). Inference making while reading narrative and expository texts: An ERP study. Psychology \& Neuroscience, 2, 2, p. 137 - 145. doi: 10.3922/j. psns.2009.2.005.

Beeman, M. (1993). Semantic processing in the right hemisphere may contribute to drawing inferences from discourse. Brain and language, 44, p.80-120.

Beeman, M., Bowden, E.M. \& Gernsbacher, M.A. (2000). Right and left hemisphere cooperation for drawing predictive and coherence inferences during normal story comprehension. Brain and language, 71, p. 310-336.

Bogen, J. E. (1997). Does cognition in the disconnected right hemisphere require right hemisphere possession of language? Brain and Language, 57, p.12-21.

Brown, C. \& Haggort, P. (2000). On the electrophysiology of language comprehension: implications for the human language system. In M.W. Crocker, M. Pickering \& Jr. C. Clifton (Eds.), Architectures and mechanisms for language processing (pp. 213-237). Cambridge University Press.

Code, C. (1997). Can the right hemisphere speak? Brain and Language, 57, p.38-59.

Coles, M. G. H. \& Rugg, M. D. (1995). Event-related brain potentials: an introduction. In M. G. H. Coles \& M. D. Rugg (Eds.), Electrophysiology of mind: Event-related brain potentials and cognition (pp. p.1-26). Oxford, New York: Oxford University Press.

Coulson, S. \& Lovett, C. (2004). Handedness, hemispheric asymmetries and joke comprehension. Cognitive brain research, 19, p.275-288.

Coulson, S. \& van Petten, C. (2002). Conceptual integration and metaphor: an event-related potential study. Memory and Cognition, 30(6), p. 958968.

Federmeyer, K.D \& Kutas, M. (1999). Right words and left words: electrophysiological evidence for hemispheric differences in meaning processing. Cognitive Brain Research, 8, p.373-392. 
Federmeyer, K.D, May, H. \& Kutas, M. (2005). Both sides get the point: hemispheric sensitivities to sentencial constraint. Memory \& Cognition, 33(5), p. 871-886.

Gazzaniga, M.S, Eliassen, J.C., Nisenson, L., Wessinger, C.M, Fendrich, R. \& Baynes, K. (1996). Collaboration between the hemispheres of a callosotomy patient: emerging right hemisphere speech and left hemisphere interpreter. Brain, 119, p.1155-1262.

Heny, J. (1998). Brain and language. In V.P. Clark, P.A. Eschholz, \& A.F. Rosa (Eds). Language: reading in language and culture (pp. 634-657). New York: St. Martin's Press

Jung-Beeman, M. (2005). Bilateral brain processes for comprehending natural language. TRENDS in Cognitive Sciences, vol. 9(11), p.512-518.

Kutas, M., \& Hilliard, S.A. (1983). Event-related. Brain potentials to grammatical errors and semantic anomalies. Memory and Cognition, 11, 539-550.

Kutas, M., \& Hilliard, S. A. (1984). Brain potentials during reading reflect word expectancy and semantic association. Nature, 307, p.161-163.

Kutas, M. \& van Petten, C. (1994). Psycholinguistics electrified: eventrelated brain potential investigations. In A.M. Gernsbacher, (ed.) Handbook of Psycholinguistics (pp. 83-142). San Diego, CA: Academic Press.

Kutas, M. \& Schmitt, B. M. (2003). Language in microvolts. In M. T. Banich, \& M. Mack, (Eds.) Mind, brain and language - multidisciplinary perspectives. (pp. 171-209). Mahwah, New Jersey: Lawrence Erlbaum Associates.

Lundy-Ekman, L. (2000). Neurociência - fundamentos para a reabilitação. Rio de Janeiro: Editora Guanabara Koogan. Ch. 17.

Mason, R. A., \& Just, M. A. (2004). How the brain processes causal inferences in text: A theoretical account of generation and integration component processes utilizing both cerebral hemispheres. Psychological Science, 15, p. 1-7.

Mueller, J. L.; Hirotani, M. \& Friederici, A. (2007). ERP evidence for different strategies in the processing of case markers in native speakers and nonnative learners. BMC Neuroscience, 8. doi:10.1186/1471-2202-8-18. 
Newman, S., Just, M. \& Mason, R. (2004). Compreendendo o texto com o lado direito do cérebro - o que os estudos de neuroimagem funcional têm a dizer. In C. Rodrigues \& L.M.B. Tomitch, (Eds.) Linguagem e cérebro humano - contribuições multidisciplinares. (pp. 71-86). Porto Alegre: Artmed,

Nichelli, P., Grafman, J. Pietrini, P., Clark, K. Lee, K.Y. \& Miletich, R. (1995). Where the brain appreciates the moral of a story. Neuroreport, 6, p. 2309-2313.

Obler, L. K. \& Gjerlow, W. K. (1999). Language and the brain. Cambridge , U.K.: Cambridge University Press.

OCDE - Organização de cooperação e desenvolvimento econômicos. (2003). Compreendendo o cérebro - rumo a uma nova ciência do aprendizado. São Paulo: Editora Senac. Translation: Eliana Rocha.

Perfetti, C.A. \& Bolger, D.J. (2004). The brain might read that way. Scientific studies of reading, 8(3), p.293-304.

Raney, G.E. (1993). Monitoring changes in cognitive load during reading: an event-related brain potential and reaction time analysis. Journal of Experimental Psychology: Learning, Memory and Cognition, 19(1), p. 51-69.

Rosa, M. C. (2010). Introdução à (bio)linguística: linguagem e mente. São Paulo: Contexto.

Scherer, L.C. (2007). The impact of aging and language proficiency on the intermispheric dynamics for discourse processing: a NIRS study. Unpublished PhD Dissertation. Florianópolis, UFSC.

Schmalhofer, F., Friese, U., Pietruska, K., Raabe, M. \& Rutschmann, R. (2005). Brain processes of relating a statement to a previously read text: memory resonance and situational constructions. Proceedings CogSci2005: XXVIII Annual conference of the cognitive science society. July 21-23, Italy, p. 1949-1954. Available on-line at: www.cogsci.rpi.. edu/CSJarchive/Proceedings/2005/docs/p1949.pdf.

Sperber, D. \& Wilson, D. (1995). Relevance: Communication and Cognition. Oxford: Blackwell.

St. George, M. (1995). An investigation of the nature and time-course of inferences using event-related brain potentials. Unpublished doctoral dissertation. University of Delaware, Newark. 
St. George, M.; Kutas, M.; Martinez, A. \& Sereno, M.I. (1999). Semantic integration in reading: engagement of the right hemisphere during discourse processing. Brain, 122, 1317-1325.

St. George, M., Mannes, S. \& Hoffman, J. (1994). Global semantic expectancy and language comprehension. Journal of cognitive neuroscience, 6(1) 7083.

St. George, M., Mannes, S. \& Hoffman, J. (1997). Individual differences in inference generation: an ERP analysis. Journal of cognitive neuroscience, 9(6) 776-787.

Tomitch, L.M.B., Just, M.A. \& Newman, S. (2004) A neuroimagem functional na investigação do processo de leitura. In C. Rodrigues \& L.M.B. Tomitch (Eds.) Linguagem e cérebro humano - contribuições multidisciplinares (pp. 167-173). Porto Alegre: Artmed.

Tomitch, L.M.B., Newman, S., Carpenter \& Just, M.A. (2008). Comprehending the topic of a paragraph: A Functional Imaging Study of a Complex Language Process. Revista DELTA, 24(2), 175-197.

Van Berkum, Haggort, P. \& Brown, C.M. (1999). Semantic integration in sentences and discourse: evidence from the N400. Journal of cognitive neuroscience, 11(6), p. 657-671.

Van Petten C. (1995). Words and sentences: event-related brain potential measures. Psychophysiology, 32, p. 511-525.

Virtue, S., Haberman, J., Clancy, Z., Parrish, T., \& Jung-Beeman, M. (2006a). Neural activity of inferences during comprehension. Brain Research, 1084, 104-114.(a)

Virtue, S., van den Broek, P. \& Linderholm, T. (2006b). Hemispheric processing of inferences: the effects of textual constraint and working memory capacity. Memory and Cognition, 34(6), p. 1341-1354.(b)

Waldie, K.E. (2004). O papel do hemisfério direito no desenvolvimento normal e prejudicado da leitura. In C. Rodrigues \& L.M.B. Tomitch (Eds.) Linguagem e cérebro humano - contribuições multidisciplinares (pp. 177-191). Porto Alegre: Artmed.

Wilson, D. \& Sperber, D. (1993). Linguistic form and relevance. Lingua, 90, p. 1-25.

[Received in Oct. $8^{\text {th }}, 2011$. Approved in April $3^{\text {rd }}, 2012$ ] 
